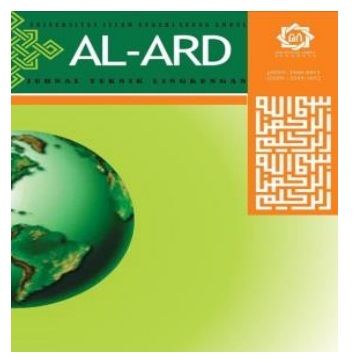

AL-ARD: JURNAL TEKNIK LINGKUNGAN

Vol.4 No.2 - Maret 2109 (01-10)

AL-ARD

JURNAL

TEKNIK LINGKUNGAN

www.al-ard.uinsby.ac.id

\title{
Pengukuran Tingkat Implementasi Rekomendasi Hasil Kajian Kinerja Lingkungan Pada Tiga UKM di Surabaya
}

\author{
Yulfiah \\ Institut Teknologi Aditama Surabaya - ITATS, Surabaya, Indonesia \\ yulfiah@itats.ac.id
}

\begin{abstract}
Small and Medium Enterprises (SMEs) in Surabaya have brought both positive and negative contributions. For this reason, two phases of research were carried out to reduce the negative effects. The first research was related to the environmental performance of three SMEs in Surabaya. The research findings recommended some activities to encourage them to have pro-action to the environment. Meanwhile, the second study conducted in the following year was with regard to the measurement of implementation rate upon the recommendation being given so as to get description on the effectiveness of recommendation. The results of this second research demonstrated that the level of implementation upon the recommendation addressed to SMEs varied about 50-90\%. Thus, the awareness of SMEs doers to make their companies environmentally friendly must be improved. The formulation of education model for SMEs is required so that the environmental performance is not only restricted to the conduct of regulation, but also becomes the obligation as it can give many benefits to company and environmental preservation. Keywords: environmental performance, performance assessment, SMEs
\end{abstract}

\begin{abstract}
Abstrak
UKM yang tersebar di Kota Surabaya, selain memberikan manfaat positif, juga memberikan dampak negatif. Terkait hal tersebut, telah dilakukan dua tahapan penelitian untuk membantu menekan munculnya dampak negatif tersebut. Tahap pertama penelitian berupa kajian kinerja lingkungan pada tiga UKM di Surabaya. Sebagai hasil kajian telah dirumuskan rekomendasi kegiatan guna mendorong UKM agar lebih pro terhadap lingkungan. Penelitian tahap kedua yang dilaksanakan setahun berikutnya, berupa pengukuran tingkat implementasi atas rekomendasi yang telah diberikan, guna mendapatkan gambaran tentang efektifitas pelaksanaan rekomendasi. Hasil penelitian tahap kedua menunjukkan bahwa, tingkat implementasi atas rekomendasi yang diberikan kepada UKM bervariasi dari 50-90\%. Dengan demikian, kesadaran pelaku UKM untuk menjadikan perusahaannya sebagai perusahaan pro lingkungan masih harus terus ditingkatkan. Dibutuhkan perumusan model edukasi kepada pelaku UKM, agar kinerja lingkungan yang dilakukan tidak sebatas lolos pentaatan ketentuan perundangan. Lebih dari itu, kinerja lingkungan yang dilaksanakan perusahaan adalah sebuah keharusan, karena mampu memberikan banyak keuntungan bagi perusahaan dan kelestarian lingkungan.

Kata Kunci: kinerja lingkungan, pengukuran kinerja, UKM.
\end{abstract}

\section{PENDAHULUAN}

Keberadaan industri memberikan banyak mafaat bagi kesejahteraan masyarakat, tidak terkecuali peran Usaha Kecil Menengah (UKM) yang mampu bertahan dalam persaingan ekonomi yang semakin ketat.

Namun demikian, UKM yang tersebar di penjuru Kota Surabaya, selain memberikan banyak manfaat positif, juga telah memberikan sejumlah dampak negatif.
Permasalahan proses produksi dan pengelolaan limbah adalah dua diantaranya.

Terkait hal tersebut telah dilakukan kajian tentang kinerja lingkungan pada tiga UKM di Surabaya. Kajian difokuskan untuk melihat dampak dari kegiatan UKM yang menjadi target penelitian terhadap lingkungan. Pada akhir kegiatan penelitian berhasil dirumuskan sejumlah rekomendasi kegiatan agar ketiga UKM yang menjadi target dalam kegiatan berikutnya lebih pro terhadap lingkungan. 
Implementasi atas rekomendasi yang telah diberikan, tentu perlu diukur guna mendapatkan gambaran tentang efektifitas pelaksanaan atas rekomendasi yang diberikan kepada UKM. Tujuan utama penelitian ini adalah untuk mengukur seberapa besar tingkat implementasi dari rekomendasi yang telah diberikan kepada UKM.

Hasil pengukuran akan memberikan manfaat bagi upaya mewujudkan kinerja UKM menjadi lebih pro lingkungan, sehingga dampak negatif dari kegiatan UKM terhadap lingkungan dapat ditekan.

Kinerja diartikan sebagai penentuan secara periodik terhadap efektifitas operasional suatu organisasi, bagian organisasi dan karyawannya berdasarkan sasaran, standar, serta kriteria yang ditetapkan sebelumnya (Mulyadi, 1997). Dengan demikian, kinerja lingkungan dapat dimaknai sebagai hasil yang dapat diukur dari sistem manajemen lingkungan, khususnya terkait kontrol aspekaspek lingkungannya, serta pengkajian kinerja lingkungan yang didasarkan pada kebijakan lingkungan, sasaran lingkungan, dan target lingkungan (ISO 14004). Menurut Ikhsan (2008), kinerja lingkungan disebutkan sebagai aktivitas-aktivitas perusahaan yang terkait langsung dengan lingkungan alam sekitarnya. Suratno dkk. (2006), menyampaikan bahwa kinerja lingkungan adalah kinerja perusahaan dalam menciptakan lingkungan yang baik dan ikut andil dalam melestarikan lingkungan.

Selanjutnya, menurut Bawley dan Li (2000) di dalam Clarkson, Peter M., Yue Li, Gordon D. Richardson, Florin P. (2006) kinerja lingkungan adalah kinerja yang dapat ditunjukkan oleh para pelaku industri dengan melaporkan kinerjanya kepada Kementerian Lingkungan Hidup untuk program terkait. Jadi, kinerja lingkungan adalah seluruh kegiatan dan aktivitas perusahaan yang memperlihatkan kinerja perusahaan dalam menjaga lingkungan, serta melaporkannya kepada pihak yang berkepentingan.

Menurut Keputusan Presiden RI No. 99 Tahun 1998, UKM dijelaskan sebagai kegiatan ekonomi rakyat berskala kecil dengan bidang usaha mayoritas merupakan kegiatan usaha kecil dan perlu dilindungi untuk mencegah persaingan usaha tidak sehat. Sementara itu, UKM yang dimaksudkan dalam penelitian ini adalah UKM yang mengacu pada jenis usaha kecil dengan kekayaan bersih tidak lebih dari
Rp 200.000.000 dan tidak termasuk tanah serta bangunan tempat usaha.

Perusahaan dikatakan pro lingkungan jika perusahaan telah melakukan kegiatan berbasis industri hijau, yaitu perusahaan yang dalam proses produksinya mengutamakan upaya efisiensi dan efektivitas penggunaan sumber daya secara berkelanjutan sehingga mampu menyelaraskan pembangunan industri dengan kelestarian fungsi lingkungan hidup serta dapat memberikan manfaat bagi masyarakat (Permen Perindustrian RI No. 18 Tahun 2016).

Sebagai bahan pengkayaan materi dalam pembahasan hasil penelitian, telah dipelajari lima penelitian dengan tema terkait. Pertama, penelitian yang dilakukan oleh Philip Shapira, Abdullah Gök, Evgeny Klochikhin, dkk (2014). Secara khusus penelitian mengkaji dan mengukur apakah suatu perusahaan telah menerapkan industri hijau. Pengukuran dan pengkajian dilakukan pada perusahaan kecil dan menengah di Inggris.

Penelitian berikutnya dilakukan oleh Sri Hartini dan Udisubakti Ciptomulyono (2015). Hasil penelitian menyampaikan bahwa manufaktur ramping bermanfaat dalam manufaktur berkelanjutan pada perspektif lingkungan dan aspek ekonomi.

Penelitian lain dilaksanakan oleh Maria Anityasari dan Aulia Nadia Rachmat (2015). Penelitian dilakukan untuk memilih beberapa perusahaan menengah potensial yang dipersiapkan untuk menerapkan prinsipprinsip industri hijau. Perusahaan ini nantinya akan diberikan bantuan teknis untuk memicu perusahaan lain agar juga menerapkan prinsip-prinsip hijau.

Andre Cantareli da Silva, Mirian Picinini Mexas, dan Osvaldo Luiz Gonçalves Quelhas (2017) telah melakukan penelitian yang ditujukan untuk mengidentifikasi serangkaian faktor yang membatasi atau menghalangi penerapan teknologi bersih dalam industri. Hasil penelitian menunjukkan, klasifikasi faktor penghambat sebagai berikut.

1. Kelembagaan, faktor ini paling menonjol karena kurangnya kebijakan insentif.

2. Keuangan/Ekonomi, berupa tidak adanya insentif keuangan.

3. Teknologi atau ketersediaan infrastruktur minimal untuk edukasi dan penelitian.

4. Sosial Budaya, berupa kurangnya pengetahuan tentang permasalahan administrasi pada bagian manajer. 
Selanjutnya Kitikorn Charmondusit, Shabbir H. Gheewala, dan Thumrongrut Mungcharoen berupaya memastikan produksi bersih benar-benar tercapai, yaitu penilaian jejak karbon, sumberdaya air, siklus hidup, dan penilaian keberlanjutan yang lebih komprehensif termasuk masalah sosioekonomi melalui penelitian yang dilakukan pada tahun 2016 .

\section{METODE PENELITIAN}

Penelitian ini dilakukan melalui dua tahap kegiatan. Penelitian tahap pertama ditujukan untuk mengkaji kinerja lingkungan pada tiga UKM di Surabaya. Dengan demikian, penelitian tahap pertama pada akhirnya berhasil merumuskan sejumlah rekomendasi bagi UKM yang didasarkan pada hasil kajian kinerja lingkungan. Pengukuran atas hasil implementasi dari rekomendasi yang diberikan merupakan kegiatan utama dari penelitian tahap kedua.

Kronologis penelitian tahap pertama meliputi kegiatan-kegiatan berikut.

1. Pemilihan tiga UKM di Surabaya yang akan menjadi target kegiatan kajian kinerja lingkungan.

2. Merumuskan materi kajian kinerja lingkungan yang diwujudkan dalam bentuk pertanyaan-pertanyaan dan dituangkan dalam kuisioner.

3. Mengirimkan kuisioner kepada UKM target untuk dilengkapi isinya.

4. Melakukan survai lapangan untuk memastikan isian kuisioner telah sesuai dengan kenyataan.

5. Melakukan kajian kinerja lingkungan berdasarkan hasil isian kuisioner dan catatan hasil survai.

6. Merumuskan rekomendasi yang harus diimplementasikan oleh UKM dengan acuan hasil kajian kinerja lingkungan yang telah dilaksanakan.

Penelitian tahap kedua dilaksanakan setahun setelah kegiatan penelitian tahap pertama selesai dilakukan. Kegiatan pengukuran implementasi atas rekomendasi yang diberikan kepada UKM sebagai penelitian hasil penelitian tahap pertama, diselenggarakan melalui kegiatan survai lapangan. Penilaian diberikan sesuai ceklist yang telah dibuat.

Pada akhir kegiatan penelitian tahap kedua dibuat kesimpulan yang menggambarkan efektifitas dari implementasi rekomendasi, khususnya pada peningkatan kinerja UKM yang lebih pro terhadap lingkungan.

\section{HASIL DAN PEMBAHASAN}

Berikutnya disajikan hasil penelitian yang telah dilaksanakan pada Tabel 1, Tabel 2, dan Tabel 3. Penelitian untuk melakukan pengukuran implementasi rekomendasi, diselenggarakan pada tiga UKM, yaitu di CV. Adi Saputra, CV. Go Hong Bun, dan CV. Sriwijaya. Ketiga UKM tersebar pada kawasan Surabaya Timur dan Surabaya Barat. UKM pertama bergerak di bidang usaha elektroplating. UKM kedua adalah industri tahu. Sementara UKM ketiga merupakan perusahaan yang memproduksi karet gelang.

Profil ketiga perusahaan secara garis besar memperlihatkan bahwa semua perusahaan telah relatif lama beroperasi, yaitu berdiri sejak tahun 1959-1986. Kondisi ini mengakibatkan, peralatan produksi sebagian besar telah berkarat sehingga beresiko mengkontaminasi produk, khususnya pada tiga industri tahu. Bangunan pabrik pun nampak rapuh dan kurang terawat. Semua industri merupakan perusahaan keluarga, sehingga manajemen yang digunakan masih relatif sederhana, tidak terlihat adanya inovasi cukup berarti. Apa yang dilakukan perusahaan saat ini, hanyalah berdasarkan pada pengalaman yang diwariskan. Kondisi demikian mengakibatkan adanya kecenderungan menurunnya kapasitas produksi, karena kalah bersaing dengan perusahaan baru yang lebih modern.

Dari sisi perijinan, semua perusahaan telah patuh terhadap perundangan, minimal semua perusahaan memiliki dokumen perijinan sesuai bidang usaha masing-masing. Khusus pentaatan terhadap ketentuan perundangan terkait permasalahan lingkungan hidup, pemenuhan perijinan hanya sebatas lolos kewajiban. Pada ketentuan pengolahan limbah misalnya, perusahaan dapat menunjukkan dokumen perijinannya. Namun, kenyataan di lapangan, memperlihatkan bahwa Instalasi Pengolahan Limbah (IPAL) tidak difungsikan sebagaimana mestinya. Ditemukan kesan bahwa tanggung jawab terkait permasalahan lingkungan hidup seolah hanya berada di tangan Dinas terkait. Saat pihak terkait ini, misal Badan Lingkungan Hidup, telah melakukan pengukuran terhadap limbah cair mereka, maka kewajiban industri untuk mengolah limbahnya secara tepat telah gugur. 
Pada proses produksi, perusahaan tahu menjumpai permasalahan ketersediaan pasokan kedelai sebagai bahan baku utama telah menjadi masalah pokok, termasuk juga permasalahan harga kedelai yang relatif tidak stabil. Pada semua perusahaan juga nampak kurang memperhatikan metode penyimpanan bahan baku. Demikian halnya dengan Lay out di ruang produksi yang membutuhkan pembenahan agar proses produksi dapat berjalan secara lebih efisien.

Khusus pada industri tahu, dibutuhkan inovasi tentang penghematan air yang digunakan dalam proses produksi. Dengan diupayakannya penghematan air, maka akan mampu menekan jumlah limbah cair yang dihasilkan. Biaya pengadaan air untuk proses produksi tahu, dengan kualitas baik, nilainya relatif tinggi, sehingga menyebabkan industri lebih memilih menggunakan air yang tidak layak. Hal ini menjadi pilihan agar harga produk tetap bisa bersaing. Pada semua perusahaan belum terbangun konsep proses produksi berbasis kualitas. Khusus untuk industri tahu, dibutuhkan pemahanan tentang jaminan kesehatan konsumen yang akan menikmati tahu yang mereka produksi. Termasuk masih dibutuhkannya perhatian besar pada K3 pekerja.

Pada sisi manajemen lingkungan, kebijakan lingkunga hanya sebatas pentaatan dokumen tanpa implementasi. Ini dibuktikan dengan keberadaan IPAL di setiap pabrik berkesan hanya sebagai pajangan, tanpa dioperasikan sebagaimana mestinya. Belum ada upaya jelas terkait kebijakan lingkungan. Lingkungan difahami perusahaan secara naif. Kebijakan lingkungan hanya difahami sebatas permasalahan kebersihan atau sampah, WC, atau tanam pohon. Program Lingkungan Hidup hanya bersifat praktis di lapangan, tanpa didahului studi. Kondisi ini terlihat pada bangunan saluran pembuangan yang tidak terencana, atau pemasangan kipas angin dan ventilasi yang tidak terencana.

Segala urusan perusahaan hanya di ada satu tangan, yaitu pada pimpinan perusahaan, termasuk pemahaman tentang lingkungan hidup bagi perusahaan. Pemahaman pimpinan inilah yang dianggap benar oleh seluruh staf. Padahal pemahaman pimpinan tentang lingkungan hidup sangatlah terbatas. Dengan demikian permasalahan lingkungan hidup belumlah menjadi pengetahuan bagi industri target. Semua perusahaan masih mengandalkan komunikasi lisan. Tidak dijumpai instruksi tertulis, termasuk tidak ditemukan adanya penandaan terhadap alat atau barang yang ada di tempat proses produksi

Dijelaskan oleh seluruh perusahaan bahwa mereka tidak pernah menerima komplain terkait masalah lingkungan dari masyarakat sekitar. Pernyataan ini perlu divalidasi dengan menanyakan langsung kepada masyarakat yang ada di sekitar lokasi industri.

Limbah cair pada industri electroplating perlu perhatian khusus, mengingat dari pengukuran lapangan ada indikasi bahwa limbah yang dibuang ke perairan bebas masih mengandung logam dalam jumlah besar. Pencemaran udara dan suara, juga membutuhkan perhatian lebih, agar keselamatan dan kesehatan kerja para pekerja dapat lebih terjamin.

Pencemaran suara dan debu di area pabrik karet gelang, perlu mendapat perhatian khusus, mengingat keselamatan dan kesehatan kerja para pekerja sangat mengkhawatirkan.

Pemahaman pengendapan dalam pengolahan limbah oleh semua industri target terkesan telah menyelesaikan segala permasalahannya, sehingga butuh edukasi tentang limbah industri yang mereka hasilkan, bahayanya, dan proses pengolahan yang sebaiknya dilakukan

Hasil penilaian tingkat implementasi rekomendasi hasil kajian kinerja lingkungan pada tiga perusahaan disajikan dalam Tabel 1 sampai dengan Tabel 3.

\section{KESIMPULAN}

Tingkat mplementasi atas rekomendasi yang diberikan kepada UKM bervariasi dari 50-90\%. Hal ini memperlihatkan bahwa kesadaran pelaku UKM untuk menjadikan perusahaannya sebagai perusahaan yang pro lingkungan masih harus terus ditingkatkan. Agar kinerja lingkungan yang dilakukan tidak sebatas lolos pentaatan ketentuan perundangan, dibutuhkan perumusan model edukasi kepada pelaku UKM. Kinerja lingkungan yang dilaksanakan perusahaan adalah sebuah kewajiban, karena mampu memberikan keuntungan bagi perusahaan dan kelestarian lingkungan. 
Tabel 1. Hasil Penilaian Implementasi Rekomendasi di CV. ADI SAPUTRA

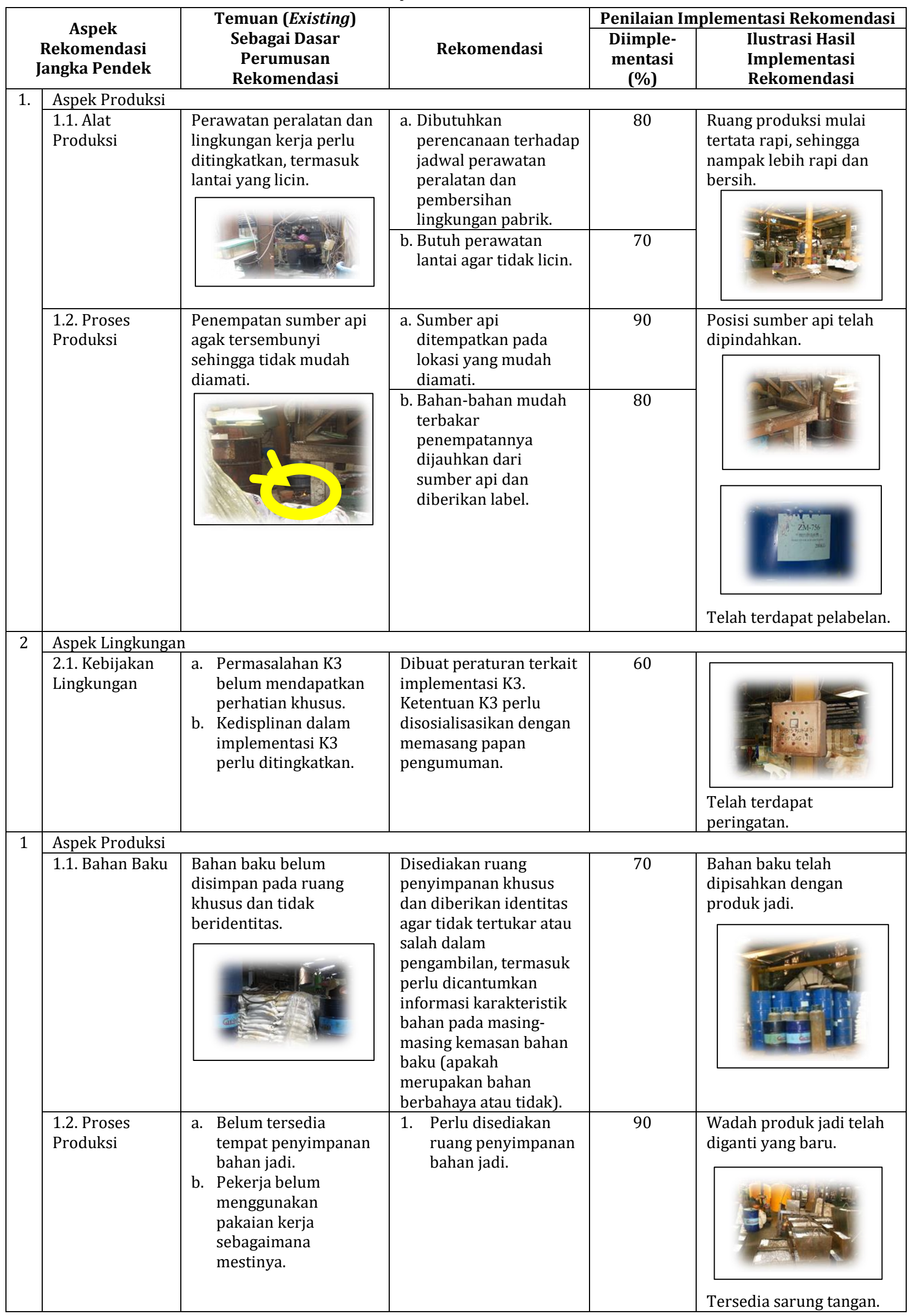




\begin{tabular}{|c|c|c|c|c|c|}
\hline \multirow{2}{*}{\multicolumn{2}{|c|}{$\begin{array}{c}\text { Aspek } \\
\text { Rekomendasi } \\
\text { Jangka Pendek }\end{array}$}} & \multirow{2}{*}{$\begin{array}{c}\text { Temuan (Existing) } \\
\text { Sebagai Dasar } \\
\text { Perumusan } \\
\text { Rekomendasi } \\
\end{array}$} & \multirow[b]{2}{*}{ Rekomendasi } & \multicolumn{2}{|c|}{ Penilaian Implementasi Rekomendasi } \\
\hline & & & & $\begin{array}{l}\text { Diimple- } \\
\text { mentasi } \\
\text { (\%) }\end{array}$ & $\begin{array}{l}\text { Ilustrasi Hasil } \\
\text { Implementasi } \\
\text { Rekomendasi }\end{array}$ \\
\hline & & & $\begin{array}{ll}2 . & \text { Dibutuhkan pakaian } \\
& \text { kerja khusus } \\
& \text { (werkpark), agar K3 } \\
& \text { pekerja terjamin. }\end{array}$ & 60 & \\
\hline \multirow[t]{3}{*}{2} & Aspek Lingkungan & & & & \\
\hline & $\begin{array}{l}\text { 2.1. Kebijakan } \\
\text { Lingkungan }\end{array}$ & $\begin{array}{l}\text { Instalasi tidak beridentitas } \\
\text { dan kurang tertata. }\end{array}$ & $\begin{array}{l}\text { Instalasi perlu dirapikan } \\
\text { guna memudahkan } \\
\text { identifikasi saat mengalami } \\
\text { gangguan. }\end{array}$ & 60 & \multirow[t]{2}{*}{$\begin{array}{l}\text { Kapasitas IPAL telah } \\
\text { ditingkatkan. }\end{array}$} \\
\hline & $\begin{array}{l}\text { 2.2. Pengendalian } \\
\text { Pencemaran }\end{array}$ & $\begin{array}{l}\text { Sistem IPAL yang ada relatif } \\
\text { sederhana. } \\
\begin{array}{|l} \\
\text {. }\end{array}\end{array}$ & $\begin{array}{l}\text { IPAL dioptimalkan efisiensi } \\
\text { penyisihannya, mengingat } \\
\text { ada indikasi limbah yang } \\
\text { dibuang belum sesuai baku } \\
\text { mutu (indikasi nilai DHL } \\
\text { yang relatif tinggi). }\end{array}$ & 80 & \\
\hline
\end{tabular}

Tabel 2. Hasil Penilaian Implementasi Rekomendasi di CV. GO HONG BUN

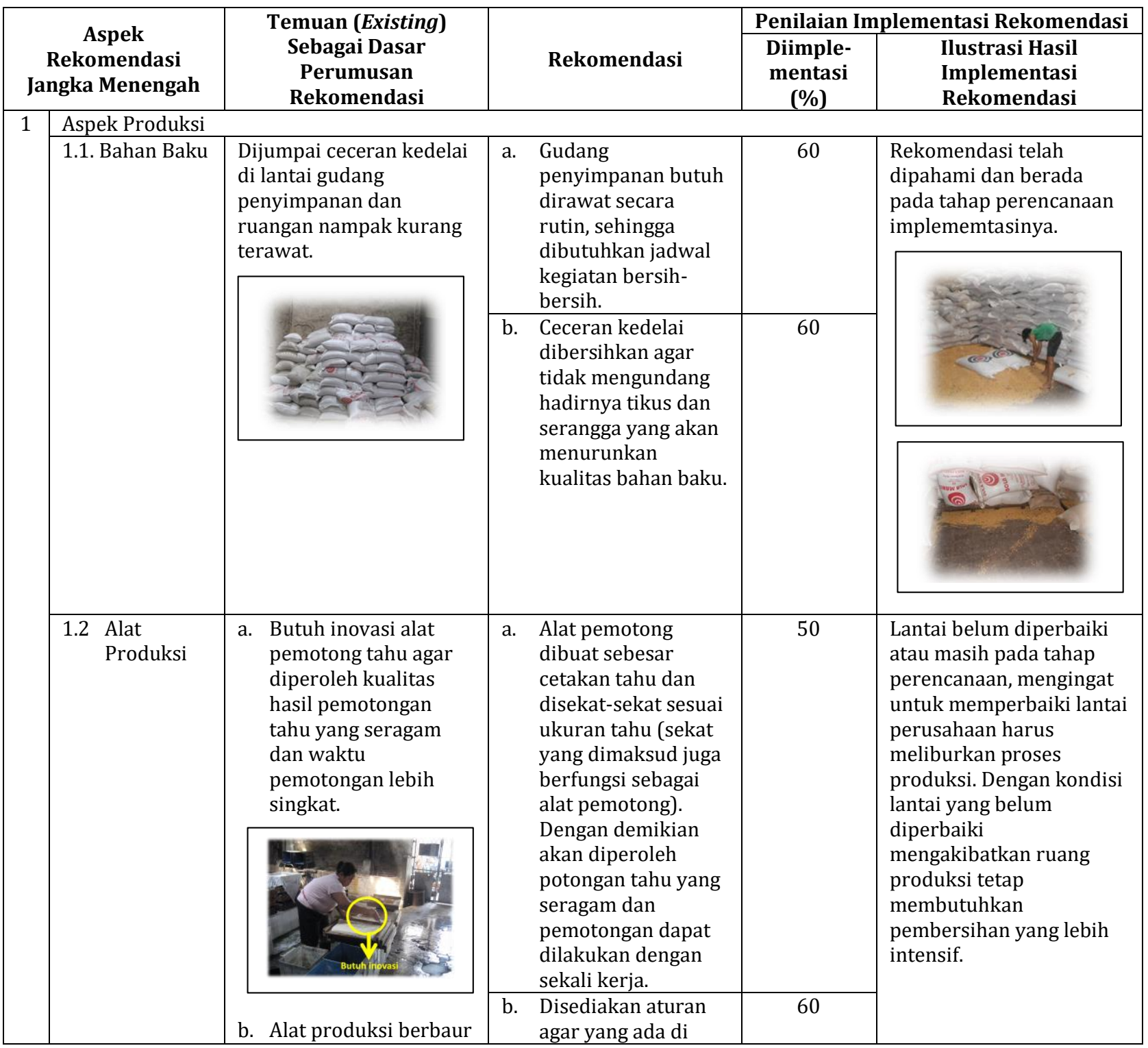




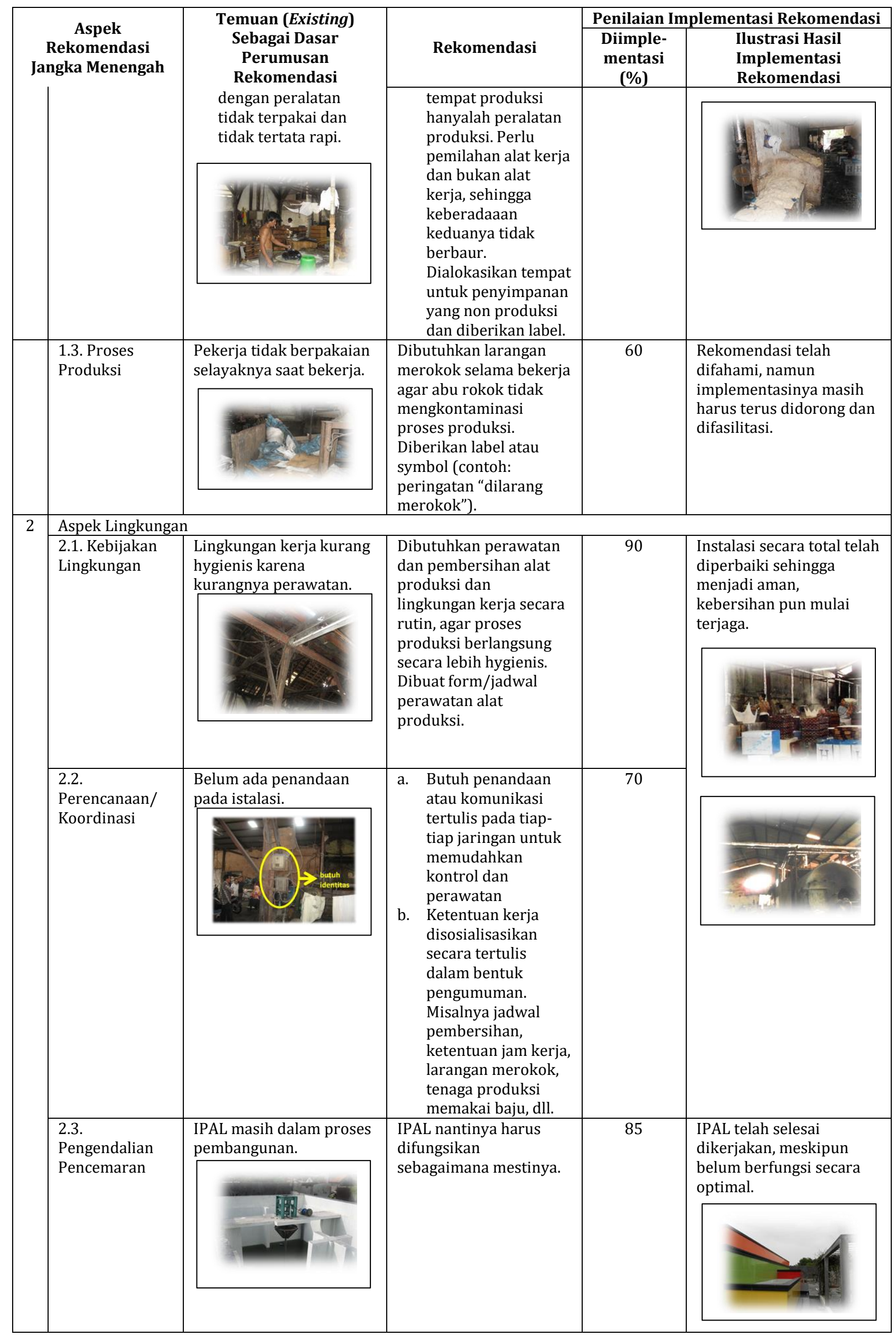




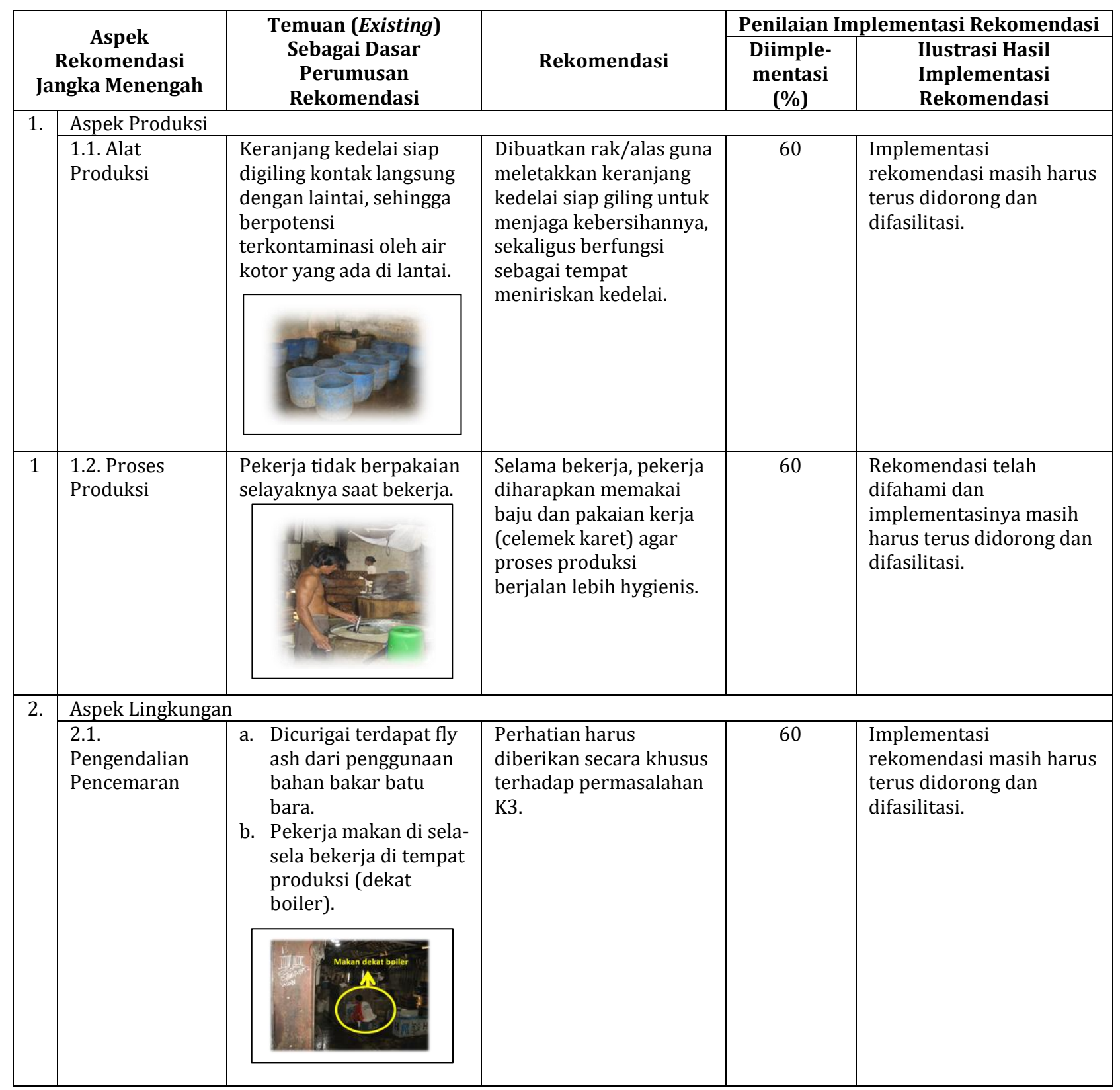

Tabel 3. Hasil Penilaian Implementasi Rekomendasi pada CV. SRIWIJAYA

\begin{tabular}{|c|c|c|c|c|c|}
\hline \multirow{2}{*}{\multicolumn{2}{|c|}{$\begin{array}{c}\text { Aspek } \\
\text { Rekomendasi } \\
\text { Jangka Pendek }\end{array}$}} & \multirow{2}{*}{$\begin{array}{c}\text { Temuan (Existing) } \\
\text { Sebagai Dasar } \\
\text { Perumusan } \\
\text { Rekomendasi } \\
\end{array}$} & \multirow[b]{2}{*}{ Rekomendasi } & \multicolumn{2}{|c|}{ Penilaian Implementasi Rekomendasi } \\
\hline & & & & $\begin{array}{l}\text { Diimple- } \\
\text { mentasi } \\
(\%)\end{array}$ & $\begin{array}{l}\text { Ilustrasi Hasil } \\
\text { Implementasi } \\
\text { Rekomendasi }\end{array}$ \\
\hline \multirow[t]{2}{*}{1.} & \multicolumn{5}{|l|}{ Aspek Produksi } \\
\hline & 1.1. Bahan Baku & $\begin{array}{l}\text { Dijumpai ceceran serbuk } \\
\text { bahan baku yang } \\
\text { berpotensi untuk }\end{array}$ & $\begin{array}{l}\text { Gudang penyimpanan } \\
\text { butuh dirawat secara } \\
\text { rutin. Ceceran serbuk }\end{array}$ & 80 & $\begin{array}{l}\text { Bahan baku tersusun rapi } \\
\text { dan ceceran mulai } \\
\text { dibersihkan. }\end{array}$ \\
\hline \multirow[t]{2}{*}{1.} & \multicolumn{5}{|l|}{ Aspek Produksi } \\
\hline & $\begin{array}{l}\text { 1.1. Proses } \\
\text { Produksi }\end{array}$ & $\begin{array}{l}\text { a. Pekerja tidak } \\
\text { berpakaian saat } \\
\text { bekerja. } \\
\text { b. Dibutuhkan standar }\end{array}$ & $\begin{array}{l}\text { Selama bekerja, pekerja } \\
\text { diberikan pakaian kerja } \\
\text { agar proses produksi } \\
\text { berjalan lebih safety. }\end{array}$ & 90 & $\begin{array}{l}\text { Pekerja telah } \\
\text { mempergunakan masker, } \\
\text { sarung tangan dan sepatu. }\end{array}$ \\
\hline
\end{tabular}




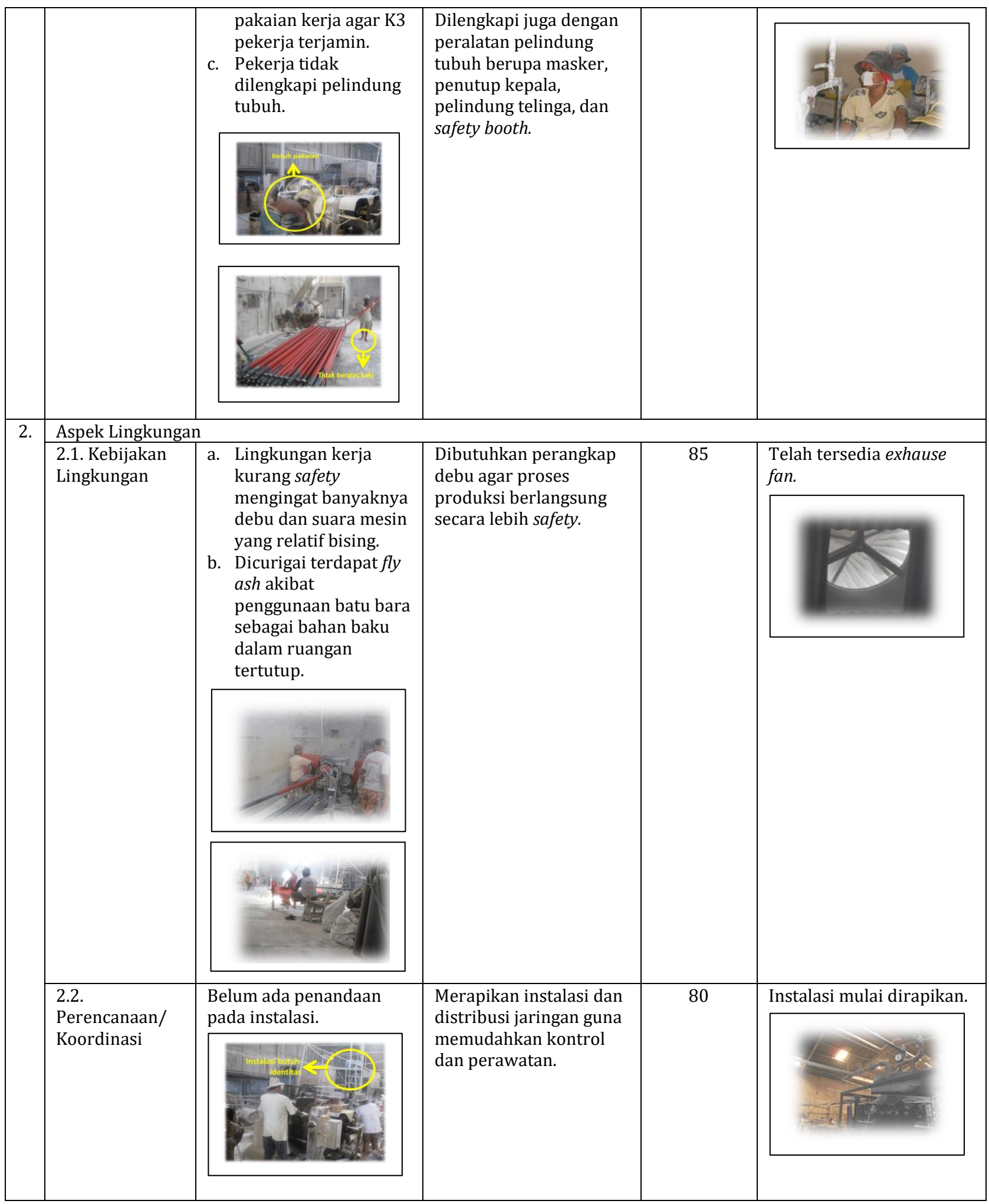

\section{DAFTAR PUSTAKA}

Anityasari, M dan Rachmat, A.N 2015. Lesson learnt from top-down selection of medium enterprises for green industry pilot project in Surabaya. Procedia Manufacturing, Industrial Engineering and Service Science.

Charmondusit, K. Shabbir, H. Gheewala, Mungcharoen, T. 2016. Green and sustainable innovation for cleaner production in the Asia-Pacific region. Journal of Cleaner Production.

Clarkson, Peter, M. Lie, Y. Gordon, D. Richardson, Florin, P. 2006. Does it really pay to be green? Determinants and Consequences of Proactive Environmental Strategies. ASAC Conference.

Hartini, S. dan Ciptomulyono, U. 2015. The relationship between lean and sustainable manufacturing on 
performance: literature review, Industrial Engineering and Service Science. IESS.

Ikhsan, A. 2008. Akuntansi Manajemen Lingkungan. Graha Ilmu. Yogyakarta.

Keputusan Presiden Republik Indonesia Nomor 99 Tahun 1998 tentang Bidang/Jenis Usaha yang Dicadangkan untuk Usaha Kecil dan Bidang/Jenis Usaha yang Terbuka untuk Usaha Menengah atau Usaha Besar dengan Syarat Kemitraan.

Mulyadi. 1997. Akuntansi Manajemen. STIE. Yogyakarta.

Peraturan Menteri Perindustrian RI Nomor. 18/M-IND/PER/3/2016 Tentang Penghargaan Industri Hijau.

Silva, A.C.D. Xas, M.P.M. Quelhas, O.L.G. 2017. Restrictive factors in implementation of clean technologies in red ceramic industries. Journal of Cleaner Production.

Shapira, P. Gok, A. Klochikhin, E. Sensier, M. 2014. Probing "green" industry enterprises in the UK: A new identification approach, Technological Forecasting \& Social Change. 